Journal of Engineering and Applied Sciences 14 (7): 2375-2384, 2019

ISSN: 1816-949X

(C) Medwell Journals, 2019

\title{
Prediction of Stresses and Strain in Soil for TBM Tunnel-FEM Anylses
}

\author{
Halah Hashiem, Waad A. Zakaria and Qasim A. Aljanabi \\ Department of Civil Engineering, Faculty of Engineering, Diyala University, Baqubah, Iraq
}

\begin{abstract}
Construction of the tunnel and the exploitation of transportation network the underground space form part of the infrastructure which becomes fundamental in large cities to treat the growing problem of mass rapid transit. The tunneling-induced volume loss of ground is an essential matter to estimate the behavior of settlement through construction and their effects on adjacent structures. The predictions of distribution and behavior of stresses and surface settlement by analysis of finite element. In this study, the prediction of the settlement caused by tunneling investigated by simulation model using the finite element method with Mohr-Coulomb depend on the case study data. The behavior of stress a round tunnel calculates and analysis the settlement during tunnel construction and compared with natural soil through various stages of construction of the tunnel. The result the behavior of stresses of the native soil and through stages of construction of tunnel using the Tunnel Boring Machines (TBM) where it shows variations of stress-depth curves between the native soil and stages construction of the tunnel for specified distances and surface settlement curve that is compatible with previous researchers.
\end{abstract}

Key words: TBM tunnel, surface settlement, FEM Model, tunnelin, native soil, predictions

\section{INTRODUCTION}

The investment of underground areas as the construction of the tunnel are part of the infrastructure development and exploitation of this space which becomes fundamental in the development of large cities. In an urban environment, the construction of tunnels induces to ground movement during the excavation process (Kolymbas, 2008). There are two major causes of movements of soil due to tunneling that are landing due to the removal of support through excavation: this causes a downward movement due to the reduction of support after the excavation and dtress relief: the stress relief mechanism causes an upward movement of soil. This is because when the soil is removed from the ground, there is a reduction in soil weight (Fattah et al., 2013).

The Tunnel Boring Machines (TBM) have been widely utilized in tunnel construction, especially, in urban areas where the most important purpose is to minimize the soil deformation. The tunnel boring machine is methodical for the excavation of tunnels with a cross-section of circular and rectangular shape through the different types of soil strata.

The continuous research and advancement in tunnel technology lead to safer and both environmentally efficient construction process and economically. Beside gaining field data to formulate empirical relationships of the ground settlement. The main difficulty is the inconsistency of soil state and applicability of the empirical formulas of various types of soil. In order to trust predict the distribution stresses and surface settlement construction tunnel by Finite Element Method (FEM) analysis has become a communal tool which can simulate staged construction procedures and reproduce the soil and structure behavior by using constitutive models (Kolymbas, 2008).

Many previous researchers such as Fattah et al. (2013) elate have studied the patterns of settlement and distribution stresses by using one of the following approaches, analytical solutions, empirical formulas, numerical solutions and physicalmodeling approach. This study discusses the approaches of models of numerical methods in predicting the behavior of stresses surrounding soil tunnel, through excavation stages and application of lining segment of the tunnel which construction by modeling of finite element method.

Literature review: Several researchers studied the patterns of settlement to estimate ground movement induced by the tunnel and to assess its potential damage to buildings using one of the following approaches such as numerical solutions.

Moller and Vermeer (2008) applied FEM to simulate the conventionally driven Steinhaldenfeld tunnel and Heinenoord slurry shield tunnel and studied the effects of the constitutive model with applied the construction

Corresponding Author: Qasim A. Aljanabi, Department of Civil Engineering, Faculty of Engineering, Diyala University, Baqubah, Iraq 


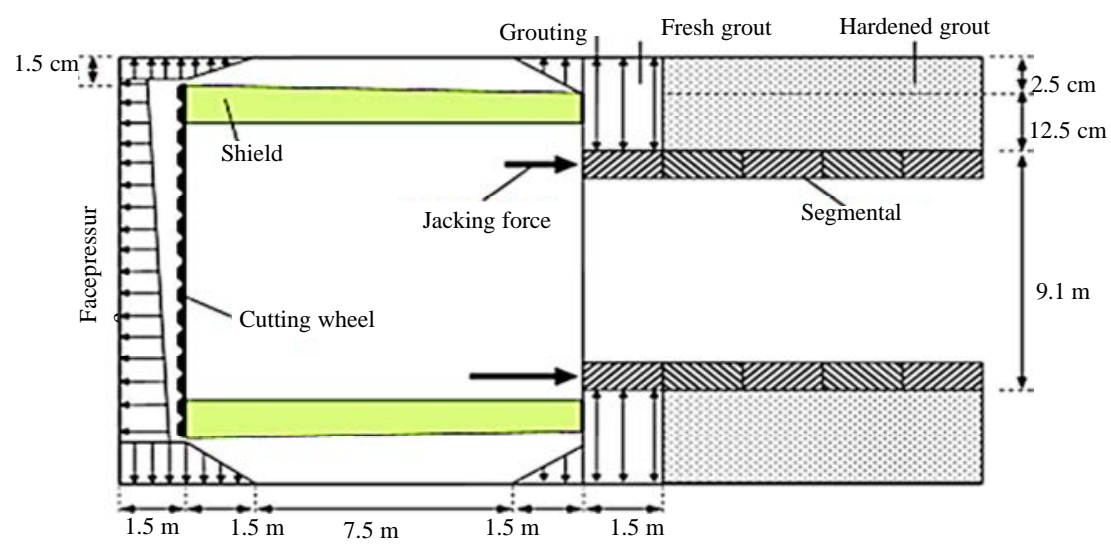

Fig. 1: The proposed of TBM system of this case

method of TBM and behavior stresses, thus, calculate ground deformation. Additional in the present study, the settlement caused by tunneling in soft soil is investigated by numerical solutions, discussion with Mohr-Coulomb and strain-hardening model and comparison with an empirical solution. While Do et al. (2013), FEM Model built using Mohr-Coulomb Model (MC) and strainhardening Constitutive Model (CY soil) which would allow showing the impact of the constitutive model of the ground on the tunnel lining behavior and displacement field surrounding the tunnel. The layout of the proposed TBM system as shown in Fig. 1. The results have shown a considerable influence of the constitutive model of the tunneling behavior and the ground displacement field. Therefore, the CY Soil Model produces a higher structural force and ground settlement values than those predicted by the MC Model.

Molins and Arnau (2011) calculates numerical the various movements caused through the construction of a shallow tunnel using a shield FEM 2D with using Mohr-Coulomb in the soil an isotropic homogeneous sandy which consisted of only one layer and at depth $10 \mathrm{~m}$ was water ground and the tunnel is circular with a diameter $\mathrm{D}$ equal to $5 \mathrm{~m}$.

The results showed the effect of the depth of the tunnel on the movements of the ground that the maximum settlement on the surface decreases with the depth of the tunnel, add to stresses behavior with depth at surface and the increase in the angle of friction decreases the intensity of the movements, thus, the results of work for this research agreed with previous studies.

Milakovic and Szavits-Nossan (2014) were shown concepts of these questions about settlement induce of tunneling by providing a numerical simulation of the tunnel in London and of the foundation pit excavation in Zagreb. The aforementioned simulation was made using

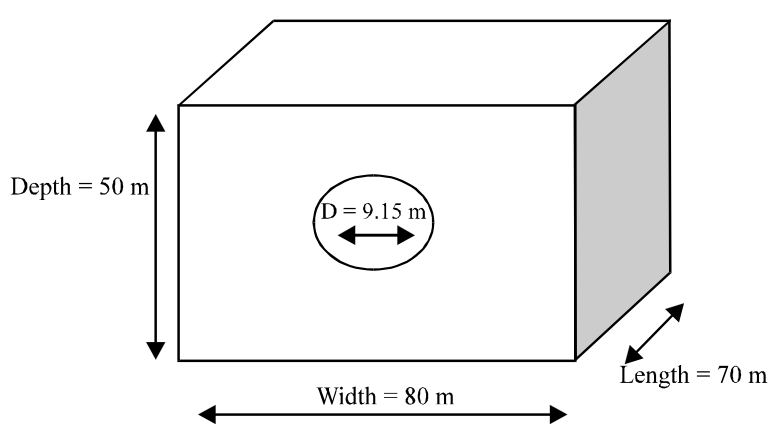

Fig. 2: Dimensions selected for the 3D FEM Model of tunnel

a widely applicable numerical soil model (finite-element method) and select the model is "Hardening soil" Model, additional taking at that into account standardly available tests for determining the spatial heterogeneity of mechanical properties of soil. The results have revealed that the influence of soil heterogeneity on the prediction of soil settlement is as calculations from in-situ measurements, soil stresses and it accounts important as the influence of soil stiffness anisotropy. Thus, the results that are acceptable for engineering practice can be obtained.

Abdelm Salam et al. (2015) where elate was simulated the conditions of a section along the route of the Greater Metro Line 3 phase 1 by doing three-dimensional finite element model employing software and compare the result of numerical methods with the actual settlement monitored during construction of the project. The data of the model, as shown in Fig. 2. The results show that the settlement of the crown and the displacement at the invert of the tunnel during all different stages of the tunnel construction and the behavior of stresses which induced caused by tunnel construction and it be noted that the 
(a)

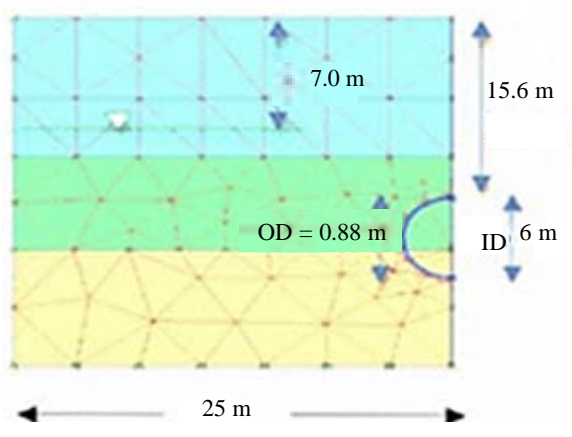

(b)

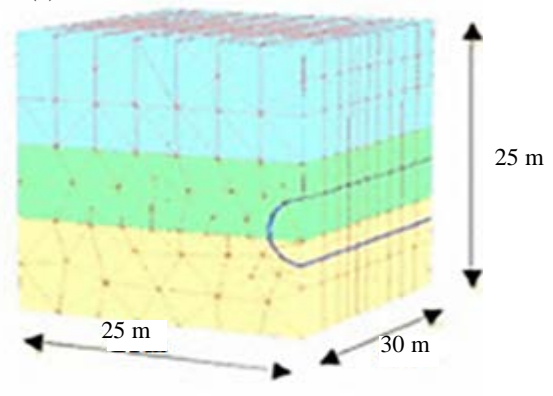

Fig. 3a, b): Geometrical configuration of stability model of the tunnel

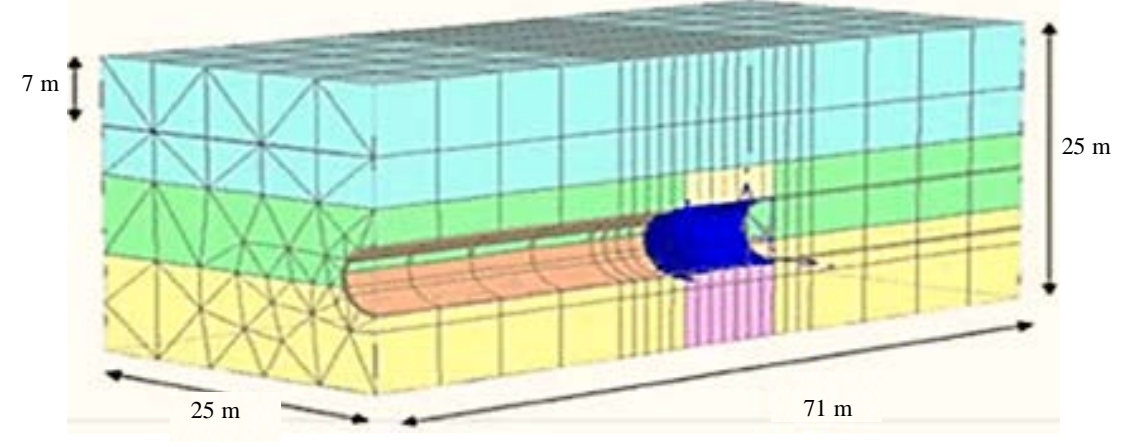

Fig. 4: Finite element mesh of deformation model of the tunnel

settlement is increasing while the TBM machine is advancing which is compatible with the well-known pattern of the TBM settlement. Consequent the results of the maximum ground surface settlement show that the numerical results are about 3.5 times the actual measured values.

While in 2016 was studied of tunnel face pressure was shown affected the geo-mechanical features of the soil along the tunnel path such as the groundwater pressure at the tunnel heading and diameter and depth of tunnel by using numerical analysis method 3D finite element and stability analysis on the construction of Shiraz subway twin tunnels in Iran between stations 5 "Ghadir" and station 6 ZahraBlvd, the geometry of the model and mesh of deformation as shown in Fig. 3 and 4, respectively. The research discussed the too low pressure leads to the inward collapse of the tunnel crown (active failure) that induces high surface settlements (negative displacement) while excessive pressure can result in the swelling of the head (passive failure) that induces surface heaving (positive displacement). The results in terms of tunnel deformation and surface settlement were in a good agreement with the Shiraz subway measurements by Sobhanmanesh et al. (2014) to the simulate this case study.
By Zhao et al. (2017) FEM Models for tunneling simulation and simulation the mechanized excavation of synthetic shallow and deep tunnels using $2 \mathrm{D}$ and $3 \mathrm{D}$ FEM. The simulation of the mechanized excavation of synthetic shallow and deep tunnels by using $2 \mathrm{D}$ and $3 \mathrm{D}$ FEM that shown in Fig. 5 and 6, respectively. The results of analytical and numerical solutions are compared to equivalent boundary conditions, initial conditions and identical material properties. Afterward, choice of more developed constitutive models for soil/structure (tunnel) elements in conjunction with more realistic construction sides. Hence, doing a comparison of the results in order to evaluate their applicability to calculate the lining forces and deformations for both shallow and deep tunnels. Thus the results show the lining forces, stresses and deformations depend to a large extent on the applied soil constitutive model and construction method also result shown the face support pressure, backfill grouting and arching effect cannot be which were captured appropriately in-plane strain condition which leads to the discrepancy between the model responses obtained from 2D numerical/analytical solutions and realistic 3D simulations, additional to effects of soil-lining contact properties and effects of the staged construction procedure. 


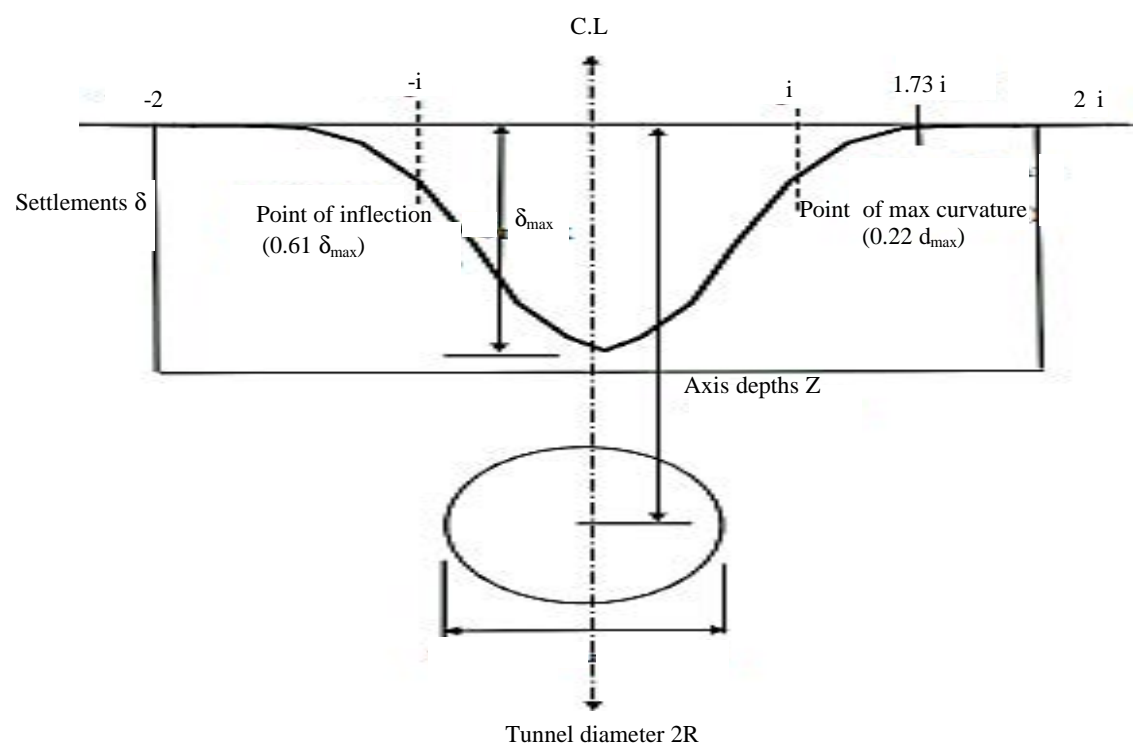

Fig. 5: Properties of error function curve to represent cross-section settlement trough above tunnel after

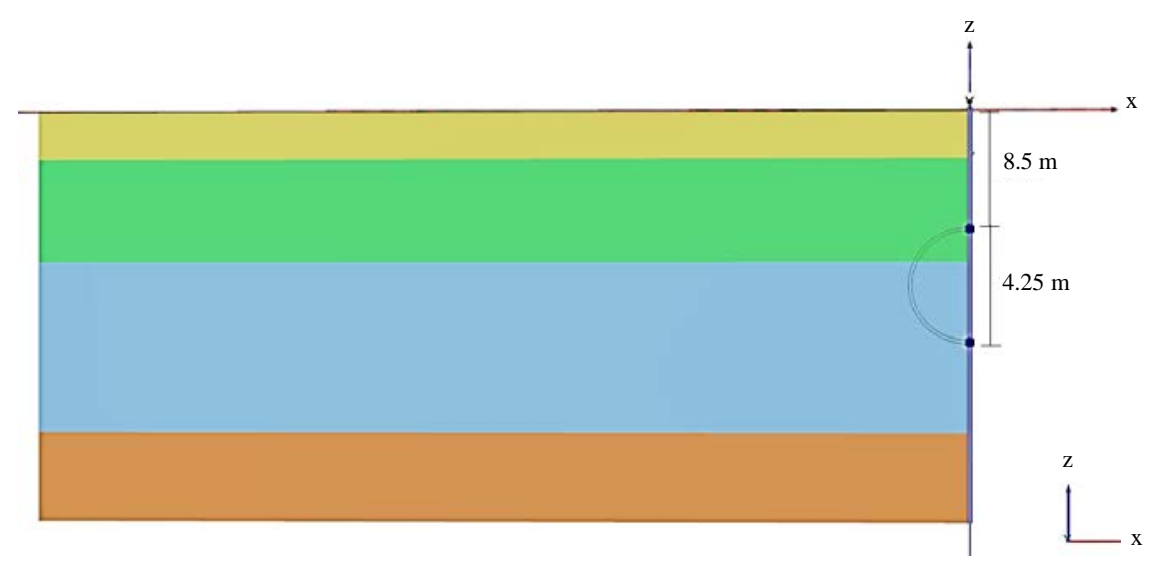

Fig. 6: The geometry of the tunnel for the 3D Model the front view

\section{MATERIALS AND METHODS}

Empirical method: Peck described settlement data from over twenty case histories. It follows that the short-term transverse settlement in the 'Greenfield' could be approximated by a normal distribution or Gaussian curve shown in Fig. 5. The equation representing the assumed settlement shape is as follows:

$$
\delta=\delta_{\operatorname{Max}} \operatorname{Exp}\left(-\mathrm{x}^{2} / 2 \mathrm{i}^{2}\right)
$$

Where:

$\delta=$ The surface settlement

$\delta_{\text {Max }}=$ The maximum vertical settlement

$\mathrm{x}=$ The transverse distance from tunnel centerline

I = The width of settlement
The Peck established a correlation between the relative depth of the tunnel and the point of inflection of transverse surface settlement trough for various soil types. In practice, the following relationship suggested by Rankin (1988) is often used:

$$
\mathrm{i}=\mathrm{k} \cdot \mathrm{Z}_{\mathrm{o}}
$$

where, $\mathrm{k}$ is a dimensionless constant, depending on soil type: $\mathrm{k}=0.5$ for clay; $\mathrm{k}=0.25$ for cohesionless soils, $Z_{0}$ is the depth of the tunnel axis $\mathrm{Z}$ is shown in Fig. 5 ground level (Rankin, 1988).

Numerical method: The available FEM is used to simulate the excavation mechanized of the tunnel. Due to the symmetry of the model, only half of the model is 
Table 1: The material properties of the concrete lining element

\begin{tabular}{llll}
\hline Parameters & Lining & TBM & Units \\
\hline Thickness & 0.25 & 0.35 & $(\mathrm{~m})$ \\
Elastic modulus & $23.5^{*} 0^{6}$ & $23.0^{*} 10^{6}$ & $\left.(\mathrm{kNlm})^{2}\right)$ \\
Unit weight & 24 & 120 & $\left(\mathrm{kN} / \mathrm{m}^{3}\right)$ \\
Poisson's ratio & 0.1500 & 0.0 & - \\
\hline
\end{tabular}

Table.2: The soil parameters of Mohr-Coulomb Model (MC)

Depth (meter)

\begin{tabular}{|c|c|c|c|c|c|c|c|}
\hline From (m) & To $(\mathrm{m})$ & $\begin{array}{c}\text { Saturation of weight } \\
\text { soil }\left(\mathrm{Kn} \mathrm{m}^{3}\right)\end{array}$ & 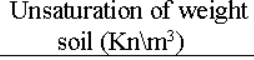 & $\begin{array}{l}\text { Young's modulus } \times \\
10^{3}\left(\mathrm{kNTm}^{2}\right)\end{array}$ & $\begin{array}{l}\text { Undrained shear strength } \\
\text { (cohesion) }\left(\mathrm{kN}^{2}\right)\end{array}$ & $\begin{array}{l}\text { Friction angle } \\
\text { degree }\left({ }^{\circ}\right)\end{array}$ & $\begin{array}{l}\text { Poisson's } \\
\text { ratio }\end{array}$ \\
\hline 0.0 & 3.5 & 19.6 & 15.6 & 25 & 27 & - & 0.30 \\
\hline 3.5 & 11 & 19.6 & 15.6 & 25 & 170 & - & 0.30 \\
\hline 11 & 23.5 & 19.6 & 14.6 & 80 & 1 & 39 & 0.25 \\
\hline 23.5 & 30 & 19.6 & 14.6 & 80 & 1 & 40 & 0.25 \\
\hline
\end{tabular}

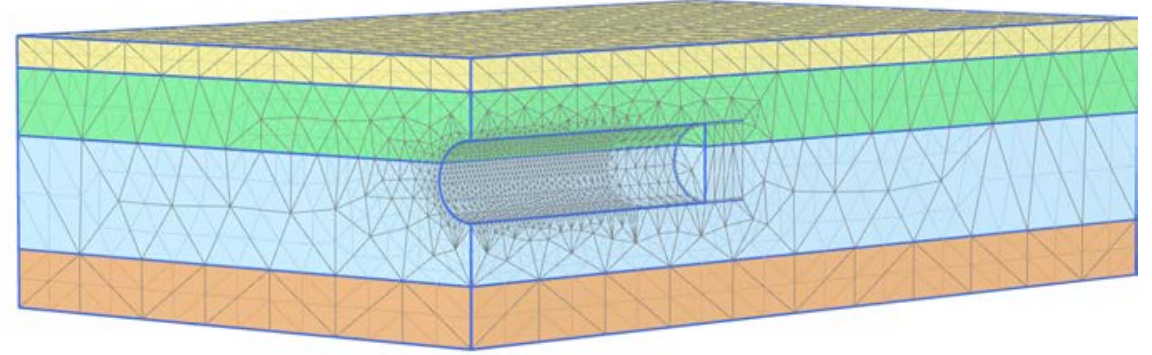

Fig. 7: Coarser type mesh of 3D geometrical of the tunnel for (MC) Model

discretized to optimize the computational cost of the numerical solution. The Diameter of the tunnel (D) is assumed to be equal to $8.5 \mathrm{~m}$ and for the longs is assumed $9 \mathrm{~m}$.

The geometry and mesh discretization for the tunnel is shown in Fig. 6 and 7 as can be seen, it is assumed that the crown of the tunnel sited at the depth of 1D. The concrete lining segments are modeled by using structural triangular elements which behavior is obeyed isotropic linear elastic constitutive. The material properties of lining elements are shown in Table 1.

The width of each precast concrete lining segment is supposed to be equal to $1.5 \mathrm{~m}$. Thus, TBM advances $1.5 \mathrm{~m}$ each step of the staged excavation. The face support pressure is applied due to averting the soil body collapse in front of the TBM. This face pressure is numerically simulated during a depth-dependent laterally distributed of load on the front soil elements.

In this research, the magnitude of face pressure is delimited with respect to the vertical stress originated from the weight of soil deposit and its gradient is $14 \mathrm{kPa} / \mathrm{m}$ associated to the unit weight of bentonite suspension whereas the magnitude of grouting pressure is known via. increasing the face pressure at the crown of the tunnel, therefore, at the same depth the magnitude of the grouting pressure is recommended to be higher than the face pressure.

The grouting pressure linearly increases from tunnel crown to invert with a gradient of $20 \mathrm{kPa} / \mathrm{m}$ which is determined based on the unit weight of the grout material. The staged excavation process is modeled by a step-wise procedure where the progressive advancement of TBM is achieved by a sequence of $1.5 \mathrm{~m}$ of soil excavation in each step.

The first six excavation steps represent the advancement of $9 \mathrm{~m}$ at long TBM-shield, the shell elements are activated with the assigned TBM material, then the installation of lining proceeds via. assigning the material of lining to the corresponding shell elements. The finite element methods support different models to simulate the behavior of soil and other continuity. The selected models will be reviewed in this study Mohr-Coulomb Model (MC)

This well-known linear elastic-perfectly plastic model is used as a first approximation of soil behavior in general. It is recommended to use this model for a first analysis of the problem considered. A constant average stiffness is estimated for the soil layer. Due to this constant stiffness, computations tend to be relatively fast and the first estimate of deformations can be obtained.

The parameters which be obtained from basic tests on soil borehole of the project and which are generally familiar to most geotechnical engineers, additional to some parameters which are adopted form Bowles (1996). Table 2 can be shown the obtain data from field and laboratory tests of the project. 

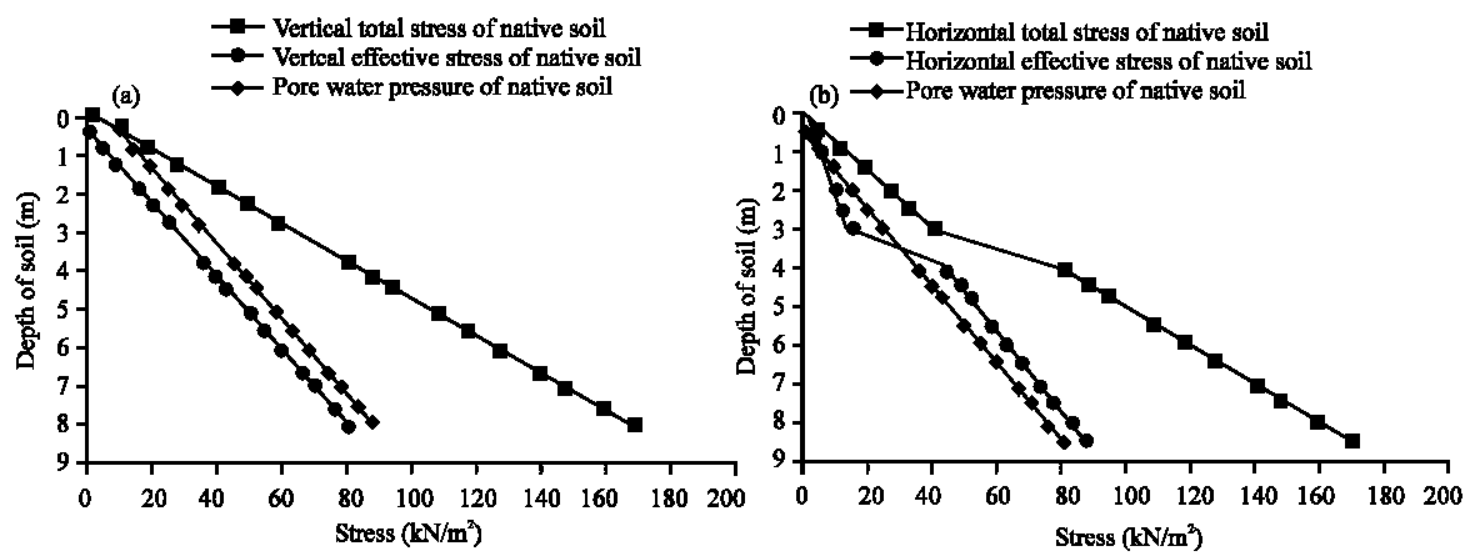

Fig. 8: Distribution stresses of native soil in a) Vertical stress and b) Horizontal stress

\section{RESULTS AND DISCUSSION}

The modeling of the Tunnel Building by using (TBM) is present a summary of the construction stages that is including the excavation of soil and apply to the lining concrete segment. The results obtained from the stresses of soil tunnel using the finite element method by failure criteria of the soil is MC Model which is shown the influence of the stress-depth curve at the upper part of the tunnel location.

The stresses surrounding tunnel zone: Figure $8 \mathrm{a}, \mathrm{b}$ is explained the total stress, effective stress and pore water stress with the depth of native soil (soil before excavation by TBM in both two direction vertical and horizontal stresses a stress points $(\mathrm{x}, \mathrm{y}, \mathrm{z})$ with deviations.

The behavior of stresses is changed through the construction of tunnel stages when the soil in front of the TBM is being excavated and support pressure is applied at tunnel face to avoid a collapse of the soil through the TBM shield will be activated while at the back of TBM the pressure will be applied grouting.

All processes are the effect on the behavior of the stresses of soil when initial position of TBM to the last segment concrete lining of the tunnel. Therefore, the paper discusses the influence of the away from the tunnel zone and advance of TBM to complete the construction, thus, the stress-depth curve shown at a different distance $(\mathrm{x})$.

At the first zone: This distance represents the data inside tunnel zone at $\mathrm{x}=0$ with deviations, Fig. 9a, b show the bahavior of the vertical and horizontal total stresses.
At the second zone: This distance represents the data inside tunnel zone at $\mathrm{x}=3$ with deviations from the tunnel centerline to show the distributions of stresses curves through stages of construction of the tunnel, Fig. 10a, b show that vertical and horizontal total stresses.

At the third zone: This distance represents the data which is far from tunnel zone at $\mathrm{x}=5 \mathrm{~m}$ with deviations from the tunnel centerline. Where are show the deviations of the stresses curves through stages of construction of the tunnel. Where begins decrease and different from the stress-depth curves at $\mathrm{x}=0$ and $\mathrm{x}=3$, Fig. $11 \mathrm{a}, \mathrm{b}$ is showing this vertical and horizontal total stresses.

At the four zone: This distance represents the data inside tunnel zone but with distance $8 \mathrm{~m}$ from the tunnel center. While are showing the deviations of the stress curves through stages construction of the tunnel where it begins identical with the native soil curve, Fig. 12a, b is showing this vertical and horizontal total stresses.

Surface settlement surrounding the tunnel zone: The value of soil movements generally depends on the soil type, construction method, tunnel dimensions and location. Ground movements around tunnels lead to surface subsidence. Figure 13 shows the total settlement of the surface occurs during the phases of construction of the tunnel.

The behavior of the surface settlement during stages construction for this model, it can be shown second phase different about other phase due to the excavations 


\section{J. Eng. Applied Sci., 14 (7): 2375-2384, 2019}

(a)
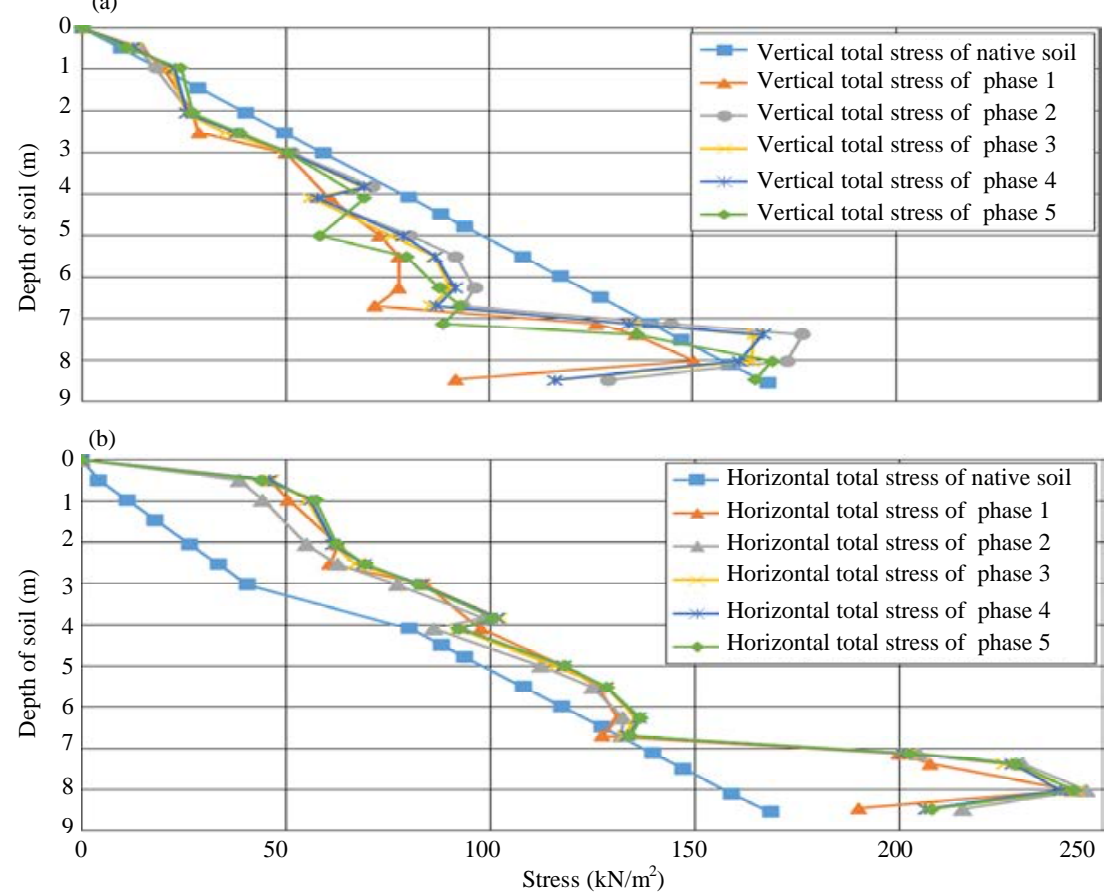

Fig. 9: Distribution of total stress $x=0$ through construction phases of the tunnel in: a) Vertical stresses and b) Horizontal stresses

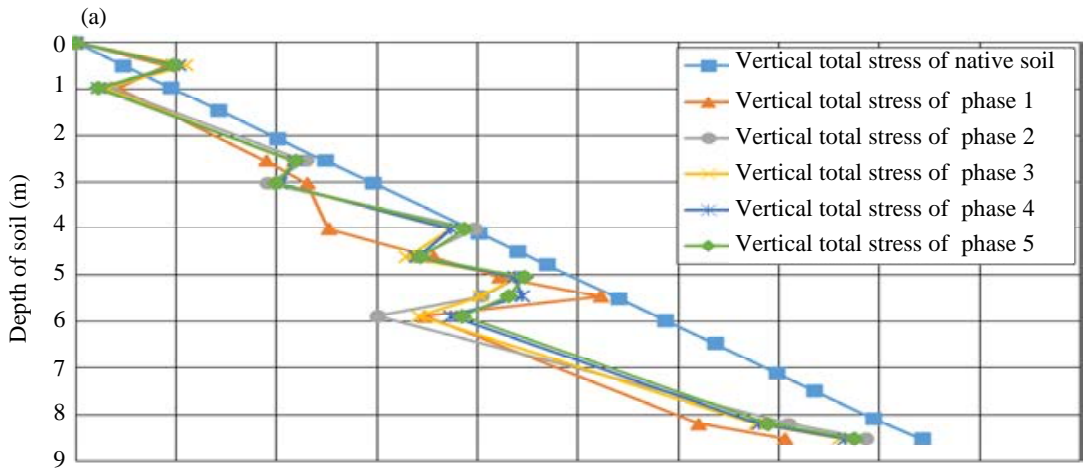

(b)

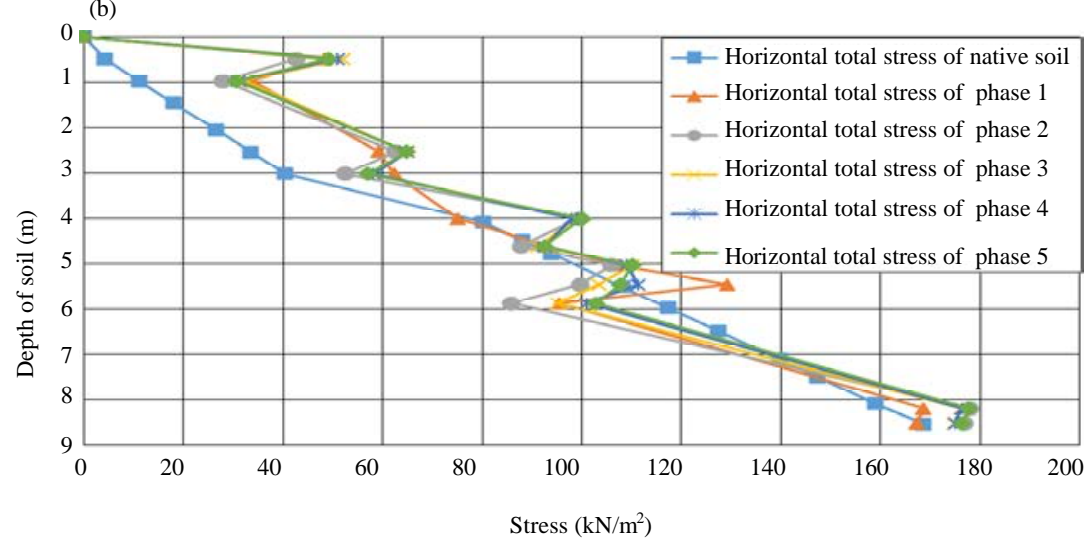

Fig. 10: Distribution of total stress $\mathrm{x}=3$ through construction phases of the tunnel in: a) Vertical stresses and $\mathrm{b}$ ) Horizontal stresses 

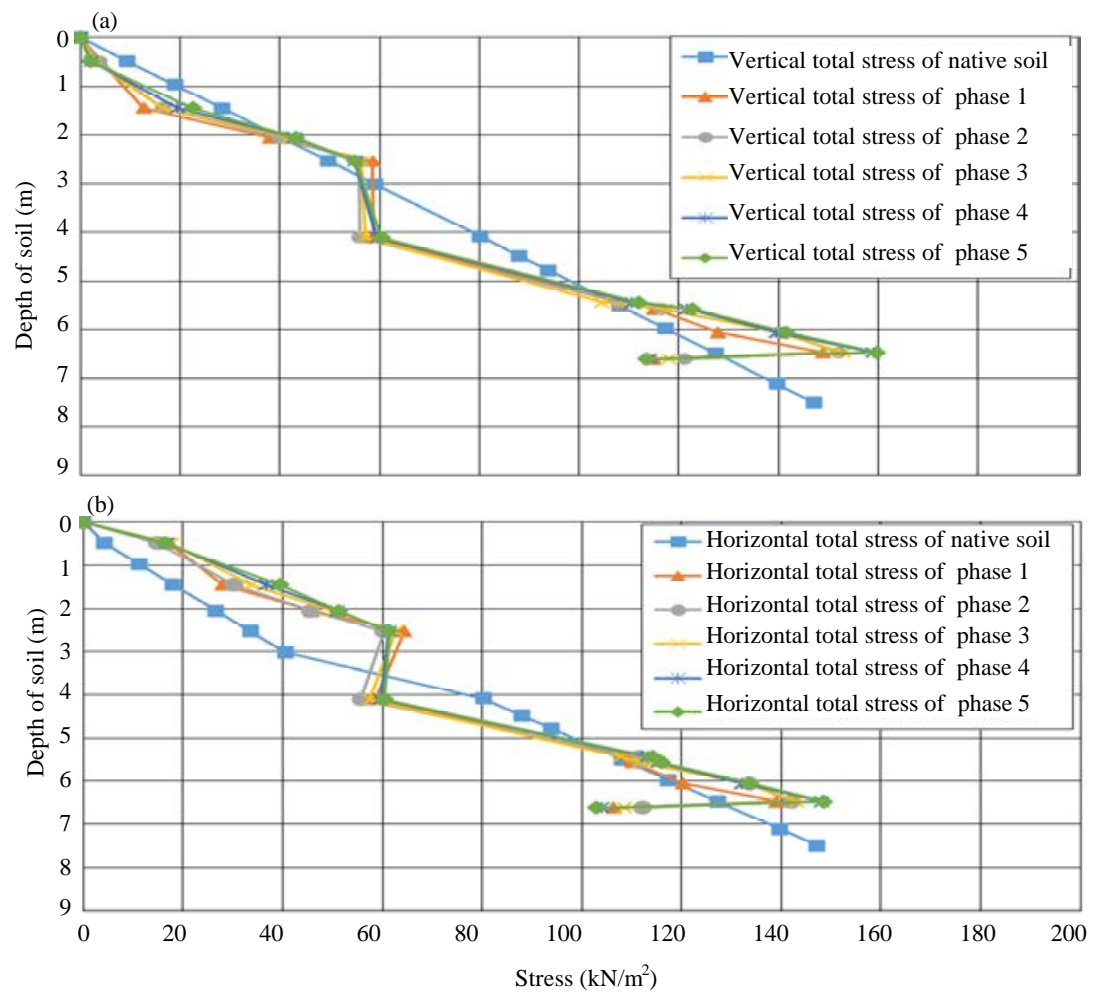

Fig. 11: Distribution of total stress $x=5$ through construction phases of the tunnel in: a) Vertical stresses and b) Horizontal stresses
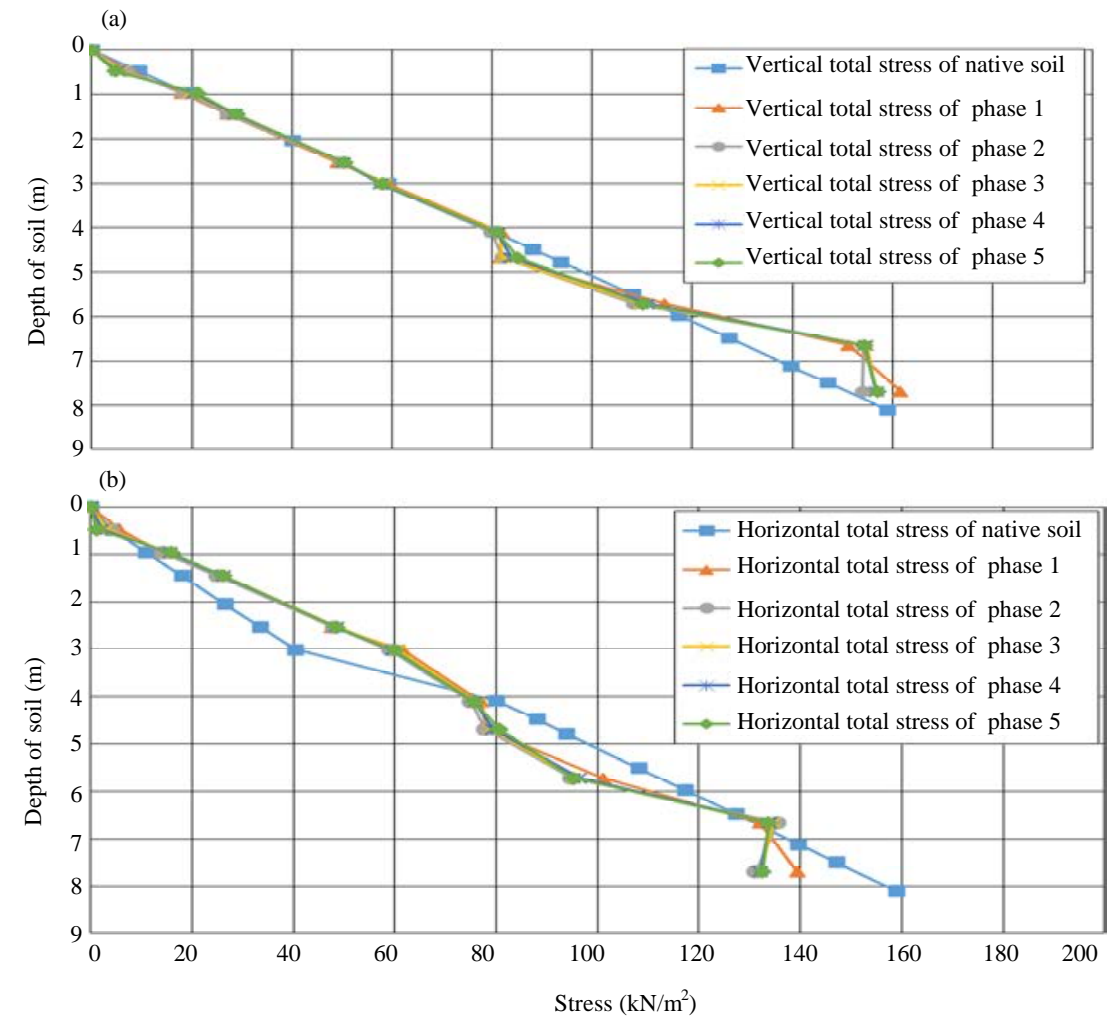

Fig. 12: Distribution of total stress $x=8$ through construction phases of the tunnel in: a) Vertical stresses and $b$ ) Horizontal stresses 


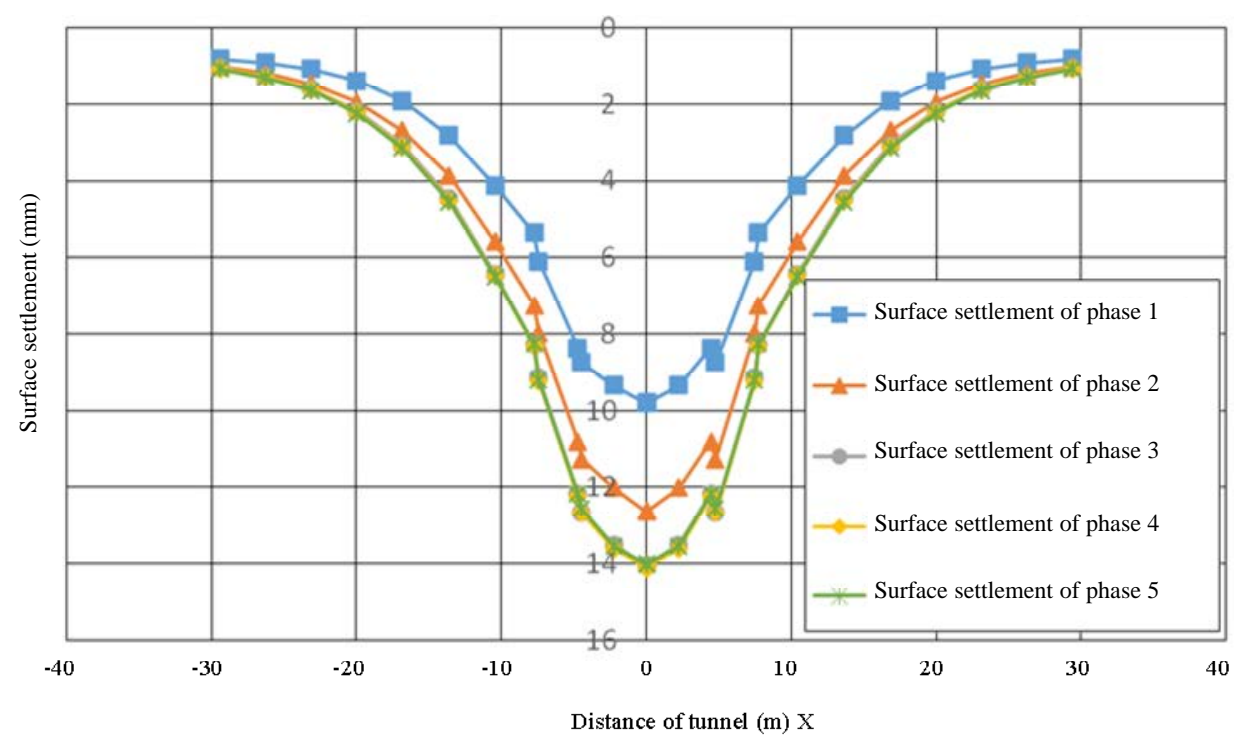

Fig. 13: Surface settlement of all the phase and comparison during stages construction

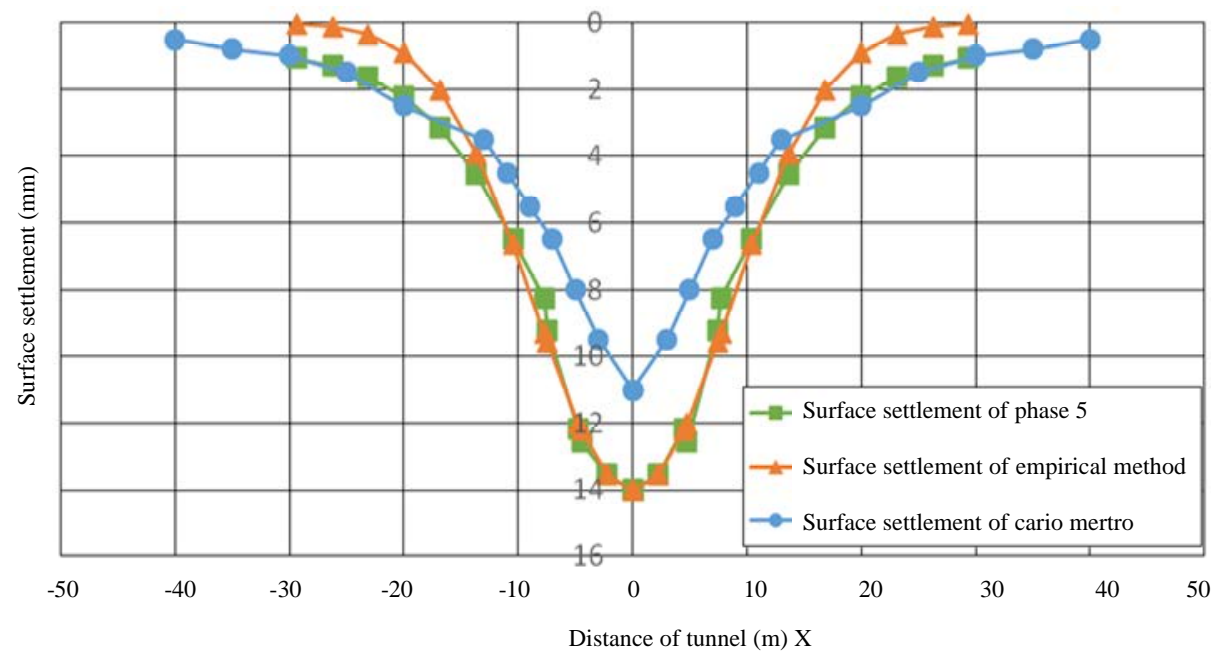

Fig. 14: Comparison between settlement with different methods

by TBM as shown in Fig. 13. The surface settlement shape of this case study is similar to shape of surface settlement which obtains by using empirical method and surface settlement of the Cairo metro (Milakovic and Szavits-Nossan, 2014) as shown in Fig. 14.

\section{CONCLUSION}

The construction of the tunnel complexes with Tunnel Boring Machines (TBM) has been widely applied in tunnel construction, especially in urban areas where the most important aim is to minimize the soil deformation. Finite element method is accepted universally as a very versatile numerical method for applied not only to the prediction of the behavior of stresses and ground settlement but also to the entire tunnel design procedures including simulation of the excavation processes and placing of the lining, soil-tunnel lining interaction. Moreover, in the field of Geotechnical engineering, it is very difficult to understand the behavior of the soil under different loading condition.

To simulate the stresses and settlement the excavation of the tunnel as the result of simulation the predication the disance, therefore, in this study, step by step excavation simulation for a tunnel has been carried out. FEM is found to be able to simulate the same and is helpful in predicting the ground subsidence. 


\section{REFERENCES}

Abdelm Salam, S., A. Ata, O. Shaalan and N. Hammad, 2015. Modeling of TBM tunnel construction for the greater cairo metro line 3 . Intl. J. Eng. Innovative Technol., 4: 18-24.

Bowles, J.E., 1996. Foundation Analysis and Design. 5th Edn., McGraw-Hill Education, New York, USA., ISBN:9780079122476, Pages: 1175.

Do, N.A., D. Dias, P. Oreste and I. Djeran-Maigre, 2013. 3D modeling for mechanized tunneling in soft ground-influence of the constitutive model. Am. J. Appl. Sci., 10: 863-875.

Fattah, M.Y., K.T. Shlash and N.M. Salim, 2013. Prediction of settlement trough induced by tunneling in cohesive ground. Acta Geotech., 8: 167-179.

Kolymbas, D., 2008. Tunnelling and Tunnel Mechanics: A Rational Approach to Tunnelling. Springer-Verlag, Berlin, Heidelberg, ISBN-13: 978-3540251965, Pages: 439.

Milakovic, D. and A. Szavits-Nossan, 2014. Ground settlement induced by tunnel boring in stiff clay. Gradevinar, 66: 503-512.
Molins, C. and O. Arnau, 2011. Experimental and analytical study of the structural response of segmental tunnel linings based on an in situ loading test: Part 1: Test configuration and execution. Tunnell. Underground Space Technol., 26: 764-777.

Moller, S.C. and P.A. Vermeer, 2008. On numerical simulation of tunnel installation. Tunnell. Underground Space Technol., 23: 461-475.

Rankin, W.J., 1988. Ground movements resulting from urban tunnelling: Predictions and effects. Geol. Soc. Lond. Eng. Geol. Spec. Publ., 5: 79-92.

Sobhanmanesh, A., R.B. Nazir and N. Gofar, 2014. Three-Dimensional Face Stability and Deformation Analysis of Tunneling with TBMs. In: Numerical Method in Geotechnical Engineering, Hicks, M.A., R.B.J. Brinkgreve and A. Rohe (Eds.). CRC Press, Boca Raton, Florida, USA., ISBN:9781315751825, pp:877-882.

Zhao, C., A.A. Lavasan, T. Barciaga, C. Kamper and P. Mark et al., 2017. Prediction of tunnel lining forces and deformations using analytical and numerical solutions. Tunnell. Underground Space Technol., 64: 164-176. 